\title{
Psychotropic and anti-dementia treatment in elderly persons with clinical signs of dementia with Lewy bodies: a cross- sectional study in 40 nursing homes in Sweden
}

Iris Zahirovic ${ }^{1,2^{*}}$, Gustav Torisson ${ }^{1,2}$, Carina Wattmo $0^{1,2}$ and Elisabet Londos ${ }^{1,2}$

\begin{abstract}
Background: Elderly persons with a dementia diagnosis often suffer from different neuropsychiatric symptoms (NPS) such as delusions, hallucinations, depression, anxiety, irritability and agitation. Currently, the medical treatment for NPS consists mostly of psychotropic medication such as hypnotics/sedatives, anxiolytics and antipsychotics. In elderly persons with dementia, usage of antipsychotics is less appropriate because of the risk of side effects such as parkinsonism, rapid cognitive decline, cerebrovascular events and finally mortality. Furthermore, elderly persons with dementia with Lewy bodies (DLB) are often hypersensitive to antipsychotics with numerous serious adverse events such as somnolence, sedation, extra-pyramidal symptoms, delirium and increased mortality. The aim of this study was to investigate the usage of psychotropics with a focus on antipsychotics and anti-dementia medication (according to the Anatomical Therapeutic Chemical Classification System) in elderly persons with clinical signs of DLB living in dementia nursing homes (NHs) in Sweden.
\end{abstract}

Methods: Between 2012 and 2013, we applied a specially designed questionnaire that covered the clinical DLB features according to the consensus criteria of DLB. We also collected computerized medical lists from the Swedish National Medication Dispensing System from the same period. All dementia NHs $(n=40)$ in Malmö, the third largest city in Sweden, were covered. Of 650 eligible residents, 610 (94\%) were included with 576 medical lists. The mean age was 86 years and $76 \%$ were women.

Results: Treatment with antipsychotics was seen in $22 \%$ of residents, hypnotics/sedatives in $41 \%$, antidepressants in $50 \%$ and anxiolytics in 58\%. We also found an increasing usage of antipsychotics from $25 \%$ to $43 \%$ in residents with the increasing number of DLB features. Anti-dementia medications were found in $45 \%$ of the elderly with a dementia diagnosis. However, residents with two or more DLB features had less anti-dementia medication (37\%) than the rest of the dementia-diagnosed $\mathrm{NH}$ residents (62-69\%).

Conclusions: Residents with 2-4 DLB clinical features in Swedish NHs receive an unfavourable medical treatment with high antipsychotic usage and insufficient anti-dementia medication. These findings show the importance of identifying elderly persons with DLB features more effectively and improving the collaboration with nursing care to provide better medical prescription.

Keywords: Dementia with Lewy bodies, Antipsychotics, Nursing homes, Elderly, Medication

\footnotetext{
* Correspondence: iris.zahirovic@med.lu.se; Iris.zahirovic@gmail.com

${ }^{1}$ Clinical Memory Research Unit, Department of Clinical Sciences, Lund

University, Malmö, Sweden

${ }^{2}$ Memory Clinic, Skåne University Hospital, SE-205 02 Malmö, Sweden
} International License (http://creativecommons.org/licenses/by/4.0/), which permits unrestricted use, distribution, and reproduction in any medium, provided you give appropriate credit to the original author(s) and the source, provide a link to the Creative Commons license, and indicate if changes were made. The Creative Commons Public Domain Dedication waiver (http://creativecommons.org/publicdomain/zero/1.0/) applies to the data made available in this article, unless otherwise stated. 


\section{Background}

According to the Delphi consensus study on the global prevalence of dementia in 2005, there were 24.3 million people with dementia, with a predicted doubling every 20 years [1, 2]. Dementia with Lewy bodies (DLB) is considered the second most common neurodegenerative disorder after Alzheimer's disease (AD) with both neurological and psychological symptomatology [3, 4]. According to the consensus criteria, the core clinical features of DLB are visual hallucinations, fluctuating cognition, parkinsonism and REM sleep behaviour disorder. At the later stage, elderly persons with DLB as well as other people with dementia often have neuropsychiatric symptoms (NPS) such as delusions hallucinations, depression, agitation, aggression, anxiety and irritability, with prevalence varying between $84 \%$ and $90 \%[5,6]$. The definite DLB diagnosis usually consists of Lewy bodies, Lewy neurites and amyloid plaques in different proportions [7-9]. The relation between DLB signs and DLB pathology is illustrated in a study which showed that the amount of Lewy body pathology correlated to the number of the four core DLB signs [10].

The medical treatment for NPS consists of different psychotropic medications (hypnotics/sedatives, anxiolytics, antipsychotics and anti-depressants), and mostly antipsychotics, even if the effect of both conventional and atypical antipsychotics is still questionable for improvement of some NPS $[11,12]$. In patients with dementia, usage of antipsychotics is less appropriate because of the increased risk of nursing home $(\mathrm{NH})$ admission, a more rapid cognitive decline, cerebrovascular events and finally mortality [13-16]. In addition, elderly patients with DLB are hypersensitive to antipsychotics, due to defective upregulation of dopamine 2 receptors, and in the later stage of their disease, they often live in NHs [17-19].

The US Food and Drug Administration (FDA), the European Medicines Agency (EMA) as well as the Swedish National Board of Health and Welfare (NBHW) have promoted the reduction of antipsychotics and other psychotropics and encourage the usage of other pharmacological and non-pharmacological treatments [20-23]. This is mainly because of the risk of numerous and serious adverse events such as parkinsonism, somnolence/ sedation, extra-pyramidal symptoms, delirium and finally increased mortality [16].

During the last decade, antipsychotics have been the subject of many different regulatory risk communication methods and black box warnings worldwide [24-26]. However, the usage of psychotropics is still high and according to several Swedish, Danish and Norwegian studies varies greatly $(39 \%-71 \%)$. These variations are seen in the elderly population with dementia, among the institutionalized and non-institutionalized elderly and by primary care or specialist clinic medical usage [25, 27, 28].

In a previous study of the same population, we reported an underdiagnosed prevalence of clinical DLB features in NHs [29]. The aim of the present study was to investigate the usage of psychotropic medication (antipsychotics, hypnotics/sedatives, anti-depressants, anxiolytics and anti-dementia medication) in Swedish NHs with a special focus on patients with clinical features of DLB.

\section{Methods \\ Study design}

The study material consists of data from the dementia $\mathrm{NH}$ residents in Malmö, the third largest Swedish city with over 320,000 inhabitants. To gather accurate information on the actual number of dementia NHs, for the period 2012-2013, we contacted the head account manager for dementia NHs in the city of Malmö. Thereafter, from January 2012 to March 2013, we invited all 40 dementia NHs in Malmö to participate in the study. All residents aged $\geq 65$ years had the same electronic hospital medical record system and updated medical lists during the study period.

\section{Nursing homes}

The NHs in Malmö each housed an average of 15 elderly residents (range 4-45) with a staff consisting of a resident physician (specialist from primary care), 1 or 2 head nurses (with 3 years of university) and a varying number [4-8] of assistant nurses (with 2 years of nursing care school). The elderly residents either already had a dementia diagnosis or were undergoing a dementia investigation procedure. All resident physicians are requested to follow the guidelines for dementia investigation from the Swedish NBHW [30]. The minimal investigation, the so-called "Basal dementia investigation", consists of cognitive testing (Mini-Mental State Examination, cube and clock drawing tests), relevant laboratory tests, cone beam computed tomography (CBCT) and/or magnetic resonance (MR) imagining (evaluated by a radiologist) and structural anamnestic interview by the doctor (patient and family members).

The elderly person becomes an NH resident after a decision made by a care organizer from the local authority (communal/municipal) following care planning with the elderly person, the family members and a doctor or head nurse who had consulted with the doctor.

\section{Data collection}

The inclusion criterion was all residents living at NHs $\geq 65$ years. The exclusion criterion was residents in a palliative state of treatment. The main clinical outcome measure was a questionnaire that was specially designed 
to cover clinical signs of DLB according to the consensus criteria from the third report of the DLB Consortium [7] but also compatible with the diagnostic form of DLB Diagnostic Symptoms of the Lewy Body Dementia Association [31]. We decided to choose observable descriptions of possible DLB signs. Prior to entering the study, each $\mathrm{NH}$ separately received a specially designed presentation seminar given by a resident physician (IZ) to all nursing staff. For this study, there was also the opportunity of individual medical education, clarification and answering questions from the nursing staff (head nurses and assistant nurses). There were also possibilities for the resident physician to demonstrate to the nursing staff how the clinical features from the questionnaire could be expressed in practice in the elderly (with their verbal consent) living in NHs. The nursing staff were instructed to register the presence/absence of seven actual clinical features at the time of scoring: 1) Parkinson's disease (PD) or parkinsonism; 2) rigidity, signs of stiffness; 3 ) tremor and/or a rigid posture and walk; 4) a weak voice; 4) balance problems, dizziness, faints, falling easily and/or more frequently; 5) visual hallucinations; 6) excessive daytime sleepiness, variations in attention and wakefulness; and 7) sleep disorder, acting out dreams during sleep (sometimes violently), shouting out at night, nightmares. A more detailed description of the questionnaires is presented in an earlier publication [29].

\section{Medical data}

During the same period, the head nurse collected actual medical lists from the Swedish National Medication
Dispensing System (NMDS) together with the questionnaire. From the computerized hospital medical records, we collected data on dementia diagnoses (yes/no and dementia type). From the medical lists, we categorized the psychotropic medicines according to the Anatomical Therapeutic Chemical (ATC) Classification System: antipsychotics (N05A), anxiolytics (N05B), hypnotics/sedatives (N05C), anti-depressants (N06A) and antidementia medicine (N06D) [32].

\section{Statistical analysis}

For the statistical analysis, we used the IBM Statistical Package for the Social Sciences (SPSS) for Windows (version 22.0; IBM Corporation, Armonk, NY, USA). For comparisons of two independent groups, we used the Student's $t$ test for normally distributed data and the Mann-Whitney $U$ test for non-parametric data. NH residents were divided into dichotomous groups: dementia (yes/no), DLB signs (0-1 DLB and 2-4 DLB) and age ( $\leq 85$ and $\geq 86$ years) (Tables 1,2 and 3 ). Categorical data were investigated using the chi-squared test. The significance level was set to $P<0.05$. A Bonferroni correction for multiple testing of the groups was applied by setting the $P$-value at $<0.01$.

\section{Results}

\section{Study population}

In this study, $40 \mathrm{NHs}$ with 650 residents were invited to participate. Of these, 30 residents declined participation and 10 had missing data. Thus, the final study population consisted of 610 elderly residents with collected

Table 1 Demographics

\begin{tabular}{|c|c|c|c|c|c|}
\hline & $\begin{array}{l}\text { Study } \\
\text { population } \\
\mathrm{N}(\%)\end{array}$ & $\begin{array}{l}\text { DLB 0-1 } \\
\text { N }(\%)\end{array}$ & $\begin{array}{l}\text { DLB 2-4 } \\
N(\%)\end{array}$ & $\begin{array}{l}\text { Anti-dementia } \\
\text { medication }^{c} \\
\mathrm{~N}(\%)\end{array}$ & $\begin{array}{l}\text { Antipsychotic } \\
\text { medication }^{d} \\
\text { N (\%) }\end{array}$ \\
\hline \multicolumn{6}{|l|}{ Sex N (\%) } \\
\hline Male & $146(24)$ & $112(77)$ & $34(23)$ & $51(38)$ & $31(21)$ \\
\hline Female & $464(76)$ & $374(81)$ & $90(19)$ & $141(32)$ & $101(22)$ \\
\hline \multicolumn{6}{|l|}{ Dementia diagnosis } \\
\hline Yes N (\%) & $440(74)$ & $348(79)$ & $92(21)$ & $192(45)$ & $102(23)$ \\
\hline \multicolumn{6}{|c|}{ Different dementia diagnoses ${ }^{e}$} \\
\hline Alzheimer's disease & $115(26)$ & $92(80)$ & $23(20)$ & $71(64)$ & $30(26)$ \\
\hline Alzheimer's mixed & $97(22)$ & $83(86)$ & $14(14)$ & $66(69)$ & $25(26)$ \\
\hline Vascular dementia & 85 (19) & $69(81)$ & $16(19)$ & $5(6)$ & $20(24)$ \\
\hline DLB/PDD ${ }^{f}$ & $22(5)$ & $2(9)$ & $20(91)$ & $13(62)$ & $5(23)$ \\
\hline Dementia NOS $^{g}$ & $121(28)$ & $102(84)$ & $19(16)$ & $37(32)$ & $22(18)$ \\
\hline
\end{tabular}

${ }^{a}$ DLB 0-1: none or one clinical feature of dementia with Lewy bodies (DLB)

${ }^{b}$ DLB 2-4: two or more DLB clinical features

${ }^{\mathrm{c} A n t i-d e m e n t i a ~ m e d i c a t i o n ~(N 06 D) ~}$

${ }^{\mathrm{d}}$ Antipsychotic medication (N05A)

eDementia diagnoses found in $440(100 \%)$ residents

fDLB/PDD: DLB/Parkinson's disease with dementia

${ }^{9}$ Dementia NOS: dementia not otherwise specified 
Table 2 Psychotropic medication

\begin{tabular}{|c|c|c|c|c|c|c|c|c|c|c|c|}
\hline & \multirow[t]{2}{*}{ ATC $^{a}$} & \multirow{2}{*}{$\begin{array}{l}\text { Study } \\
\text { population } \\
\text { N (\%) }\end{array}$} & \multicolumn{2}{|c|}{ Dementia diagnoses $^{c}$} & \multirow[t]{2}{*}{$P$-value } & \multicolumn{2}{|c|}{$\begin{array}{l}\text { Clinical signs }{ }^{d} \\
\text { of DLB }\end{array}$} & \multirow[t]{2}{*}{$P$-value } & \multicolumn{2}{|c|}{ Age groups $^{e}$} & \multirow[t]{2}{*}{$P$-value } \\
\hline & & & $\begin{array}{l}\text { Yes } \\
\text { N (\%) }\end{array}$ & $\begin{array}{l}\text { No } \\
\text { N (\%) }\end{array}$ & & $\begin{array}{l}0-1 \\
N(\%)\end{array}$ & $\begin{array}{l}2-4 \\
N(\%)\end{array}$ & & $\begin{array}{l}\leq 85 \text { years } \\
N(\%)\end{array}$ & $\begin{array}{l}\geq 86 \text { years } \\
N(\%)\end{array}$ & \\
\hline \multicolumn{12}{|l|}{ Antipsychotics } \\
\hline Any & N05A & $132(21.6)$ & $102(23.2)$ & 29 (18.8) & & $93(19.1)$ & 39 (31.5) & * & $71(27.4)$ & $61(17.4)$ & $* *$ \\
\hline Haloperidol & & $42(7.1)$ & $28(6.6)$ & $14(9.3)$ & & $25(5.3)$ & $17(14.3)$ & $* *$ & $23(9.3)$ & $19(5.5)$ & \\
\hline Risperidone & & $57(9.6)$ & 49 (11.5) & $8(5.3)$ & & $45(9.5)$ & $12(10.1)$ & & $29(11.7)$ & $28(8.1)$ & \\
\hline Other $^{f}$ & & $11(1.9)$ & $9(2.1)$ & $2(1.3)$ & & $7(1.5)$ & $4(3.4)$ & & $6(2.4)$ & $5(1.5)$ & \\
\hline \multicolumn{12}{|l|}{ Anxiolytics } \\
\hline Any & N05B & $336(58.4)$ & $263(61.7)$ & $73(49.0)$ & $*$ & $251(54.8)$ & $85(72.6)$ & $* * *$ & $136(56.2)$ & $200(60.1)$ & \\
\hline Oxazepam & & $308(53.6)$ & $248(58.2)$ & $60(40.3)$ & $* *$ & $228(49.8)$ & $80(68.4)$ & $* * *$ & $125(51.7)$ & $183(55.0)$ & \\
\hline Diazepam & & $44(7.7)$ & $31(7.3)$ & $13(8.7)$ & & $25(5.5)$ & $19(16.2)$ & $* * *$ & $22(9.1)$ & $22(6.6)$ & \\
\hline \multicolumn{12}{|c|}{ Hypnotics/sedatives } \\
\hline Any & N05C & $234(40.7)$ & $176(41.3)$ & $58(38.9)$ & & $186(40.6)$ & $48(41.0)$ & & $103(42.6)$ & $131(39.3)$ & \\
\hline Zopiclone & & $189(32.9)$ & $139(32.6)$ & $50(33.6)$ & & $145(31.7)$ & $44(37.6)$ & & $78(32.2)$ & $111(33.3)$ & \\
\hline Other ${ }^{g}$ & & 77 (13.4) & $67(15.7)$ & $10(6.7)$ & $* *$ & $68(14.8)$ & $9(7.7)$ & $* *$ & $39(16.1)$ & $38(11.1)$ & \\
\hline \multicolumn{12}{|c|}{ Anti-depressants } \\
\hline Any & N06A & $290(50.4)$ & $225(52.8)$ & 65 (43.6) & $* *$ & $233(48.4)$ & 57 (60.6) & * & $129(53.3)$ & $161(48.3)$ & \\
\hline SSRI & & $204(35.5)$ & $156(36.6)$ & $48(32.2)$ & & $157(34.3)$ & $47(40.2)$ & & 88 (36.4) & $116(34.8)$ & \\
\hline Mirtazapine & & $127(22.1)$ & $103(24.2)$ & $24(16.1)$ & * & 99 (20.6) & $28(29.8)$ & & $58(24.0)$ & 69 (20.7) & \\
\hline Venlafaxine & & $18(3.1)$ & $14(3.3)$ & $4(2.7)$ & & $15(3.1)$ & $3(3.2)$ & & $13(5.4)$ & $5(1.5)$ & * \\
\hline Other & & $6(1.0)$ & $4(0.9)$ & $2(1.3)$ & & $4(0.9)$ & $2(1.3)$ & & $2(0.8)$ & $4(1.2)$ & \\
\hline
\end{tabular}

${ }^{a}$ Anatomical Therapeutic Chemical (ATC) Classification System

${ }^{\text {b} A l l ~ p a r t i c i p a n t s: ~} 610$ (100\%), with registered medical lists for 575 (94\%) participants

'Dementia diagnoses: there were $(N=440)$ with a dementia diagnosis and $(N=154)$ participants without a dementia diagnosis

${ }^{\mathrm{d} C l i n i c a l}$ signs: visual hallucinations, fluctuating cognition, parkinsonism and REM sleep behaviour disorder

${ }^{\text {eAge group total }} 610(100 \%): \leq 85$ years $(N=259)$ and $\geq 86$ years $(N=351)$

fOther (N05A): Clozapine $(n=1)$, Olanzapine $(n=8)$, Quetiapine $(n=2)$

${ }^{9}$ Other (N05C): Melatonine $(n=21)$, Klometiazol $(n=58)$, Nitrazepam $(n=6)$, Propriomazin $(n=5)$

${ }^{*} P$-value $<0.05,{ }^{*} P$-value $<0.005,{ }^{* *} P$-value $<0.001$

Table 3 Anti-dementia medication

\begin{tabular}{|c|c|c|c|c|c|c|c|c|c|c|c|}
\hline & \multirow[t]{2}{*}{$\operatorname{ATC}^{a}$} & \multirow[t]{2}{*}{$\begin{array}{l}\text { Study } \\
\text { population } \\
\text { N (\%) }\end{array}$} & \multicolumn{2}{|l|}{$\begin{array}{l}\text { Dementia } \\
\text { diagnoses }^{c}\end{array}$} & \multirow[t]{2}{*}{$P$-value } & \multicolumn{2}{|c|}{$\begin{array}{l}\text { Clinical signs }^{d} \\
\text { of DLB }\end{array}$} & \multirow[t]{2}{*}{$P$-value } & \multicolumn{2}{|c|}{ Age groups ${ }^{e}$} & \multirow[t]{2}{*}{$P$-value } \\
\hline & & & $\begin{array}{l}\text { Yes } \\
\text { N (\%) }\end{array}$ & $\begin{array}{l}\text { No } \\
\text { N (\%) }\end{array}$ & & $\begin{array}{l}0-1^{11} \\
N(\%)\end{array}$ & $\begin{array}{l}2-4^{\|} \\
N(\%)\end{array}$ & & $\begin{array}{l}\leq 85 \text { years } \\
N(\%)\end{array}$ & $\begin{array}{l}\geq 86 \text { years } \\
N(\%)\end{array}$ & \\
\hline Anti-dementia drugs (All) & N06D & $192(33.3)$ & $192(45.0)$ & $0(0.0)$ & $* * *$ & $149(32.5)$ & $43(36.8)$ & & $104(43.0)$ & $88(26.3)$ & $* * *$ \\
\hline ChEl (Any) ${ }^{f}$ & N06DA & $123(21.4)$ & $123(28.8)$ & $0(0.0)$ & $* * *$ & $104(22.7)$ & $19(16.2)$ & & $67(27.7)$ & $56(16.8)$ & $* *$ \\
\hline Donepezil & N06DA & $42(7.3)$ & $42(9.8)$ & $0(0.0)$ & $* * *$ & $41(8.9)$ & $1(0.9)$ & $* * *$ & $19(7.9)$ & $23(6.9)$ & \\
\hline Rivastagmin & N06DA & $31(5.4)$ & $31(7.3)$ & $0(0.0)$ & $* * *$ & $21(4.6)$ & $10(8.5)$ & & $25(10.3)$ & $6(1.8)$ & $* * *$ \\
\hline Galantamin & N06DA & $50(8.7)$ & $50(11.7)$ & $0(0.0)$ & $* * *$ & $42(9.2)$ & $8(6.8)$ & & $23(9.5)$ & $27(8.1)$ & \\
\hline Memantin & N06DX & $100(17.4)$ & $100(23.4)$ & $0(0.0)$ & $* * *$ & $69(15.0)$ & $31(26.5)$ & $* *$ & $59(24.4)$ & $41(12.3)$ & $* * *$ \\
\hline ChEl \& Memantin & N06DA N06DX & $31(5.4)$ & $31(7.3)$ & $0(0.0)$ & $* * *$ & $24(5.2)$ & $7(6.0)$ & & $22(9.1)$ & $9(2.7)$ & $* * *$ \\
\hline
\end{tabular}

${ }^{a}$ Anatomical Therapeutic Chemical (ATC) Classification System

${ }^{\mathrm{b}}$ All participants: $610(100 \%)$, with registered medical lists for $575(94 \%)$ participants

'Dementia diagnoses: there were $(N=440)$ with a dementia diagnosis and $(N=154)$ participants without a dementia diagnosis

${ }^{d}$ Clinical signs: visual hallucinations, fluctuating cognition, parkinsonism and REM sleep behaviour disorder

${ }^{\text {e} A g e ~ g r o u p ~ t o t a l ~} 610(100 \%): \leq 85$ years $(N=259)$ and $\geq 86$ years $(N=351)$

${ }^{f} \mathrm{ChEl}$ : cholinesterase inhibitor

${ }^{*} P$-value $<0.05,{ }^{* *} P$-value $<0.005,{ }^{* * *} P$-value $<0.001$ 
medical lists for 576 (94\%), hospital medical records for 594 (97\%) and completed questionnaires for all residents. The mean age was $86( \pm 6.9)$ years and $76 \%$ were women; $74 \%$ of residents had a dementia diagnosis (Table 1).

The number of different DLB signs, from the questionnaires, were used to create two groups: residents with $0-1$ DLB signs and those with 2-4 DLB signs. In an earlier study of the same population, we reported that $84 \%$ had $0-1$ and $16 \%$ had $2-4$ main clinical features of DLB [29]. The residents with 2-4 DLB signs had the following dementia diagnoses: AD in 19\%, DLB/Parkinson's disease with dementia (PDD) in $17 \%$, dementia not otherwise specified (NOS) in 16\%, vascular dementia $(\mathrm{VaD})$ in $13 \%$, AD mixed dementia (AD-MIX) in $12 \%$ and no diagnosis in 23\%. Finally, 22 of the residents were already diagnosed with DLB/PDD, 20 (91\%) of these were classified within the 2-4 DLB signs group (Table 1).

\section{Psychotropic medication}

We found the usage of any psychotropic medication in $86 \%$ of residents. All four psychotropics (N05A, N05B, $\mathrm{N} 05 \mathrm{C}$ and $\mathrm{N06 \textrm {A }}$ ) were found in $6 \%$, three in $17 \%$, two in $31 \%$, and one in $32 \%$ of residents. We found the usage of anxiolytics in 58\%, hypnotics/sedatives in $41 \%$, antidepressants in $50 \%$ (Table 2). In addition, anti-dementia medication in $33 \%$ of residents (Table 3 ).

Usage of antipsychotics was found in $22 \%$ of the study population, most prevalently risperidone $(10 \%)$ followed by haloperidol $(7 \%)$ and other atypical antipsychotics (clozapine, olanzapine and quetiapine) (2\%) (Table 2). There was no difference in antipsychotic treatment according to sex or dementia diagnosis (yes/no). However, the age groups showed differences where younger residents ( $\leq 85$ years) had significantly more frequent usage of antipsychotics compared with those $\geq 86$ years (Tables 2 and 3 ). Furthermore, the usage of antipsychotics increased with the increasing number of main DLB signs from $25 \%$ to $43 \%$ (Fig. 1). Comparing all residents, those in the 2-4 DLB group had the highest usage of any antipsychotics (32\%) and the highest usage of haloperidol (14\%) (Table 2).

Of the participants with a dementia diagnosis, $45 \%$ had treatment with some anti-dementia medication. None of the residents without a dementia diagnosis had anti-dementia medication (Table 3). Younger residents (aged $\leq 85$ years) had significantly higher usage of some anti-dementia medication (43\%) compared with those aged $\geq 86$ years $(26 \%)$ (Table 3 ).

Comparing the 0-1 DLB and 2-4 DLB groups, there were no differences in treatment with any cholinesterase inhibitors (ChEI). However, higher usage of memantine was seen in the 2-4 DLB group (Table 3). In the group with 2-4 DLB signs, 37\% were undergoing antidementia treatment, while $62 \%$ of those already with a diagnosis for DLB/PDD were undergoing anti-dementia treatment.

\section{Discussion}

In this study, geographically covering all $40 \mathrm{NHs}$ in the third largest city in Sweden, we found an increasing usage of antipsychotics with the increasing number of DLB signs. Furthermore, residents with two or more main clinical DLB features were also receiving more antipsychotics and less anti-dementia medication compared with the rest of the NH residents. Finally, almost $40 \%$ of the residents with $2-4$ DLB signs had either dementia NOS or no dementia diagnosis, thereby being at risk for unsuitable treatment.

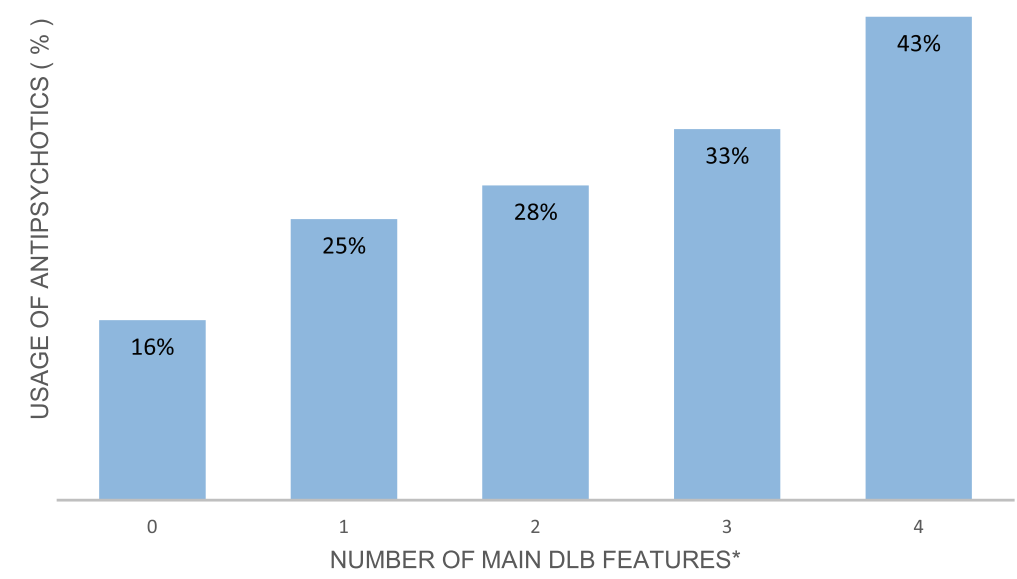

Fig. 1 Antipsychotic treatment in relation to the number of clinical DLB features. *The total number of residents with clinical features of dementia with Lewy bodies (DLB) and antipsychotic treatment. The DLB signs are: visual hallucinations, parkinsonism, fluctuating cognition, and rapid eye movement sleep behaviour disorder. $P$-value $<0.001$ 


\section{Study population}

A number of studies have emphasized the importance of identifying DLB/PDD patients at an early stage, which in turn may reduce the risk of an incorrect diagnosis, unsuitable medication, worsening of the quality of life, early $\mathrm{NH}$ admission and increased risk of shorter survival [33-37]. By dividing the study population into two groups (0-1 and 2-4 DLB signs), we could extract the high-risk residents for DLB/PDD diagnosis together with their clinical features, medical usage and actual diagnoses. The prevalence of NH residents with 2-4 DLB signs in this study was $16 \%$. Although not specifically addressed here, the observational data from clinical nurses and recorded clinical signs at the time of the study suggest that residents with 2-4 DLB signs could have undiagnosed DLB/PDD. Furthermore, over $90 \%$ of the residents already with a diagnosis for DLB/PDD from hospital medical records were in the group with 2-4 DLB signs, which indicates that the study questionnaire was efficient in identifying residents with possible DLB/ PDD (Table 1).

By using the Swedish NMDS and the hospital medical records, together with the actual clinical features reported by nursing personnel who know the residents best, we are able to present accurate medical usage for this large study population and contribute to the quality of the analysed data. Furthermore, the dementia diagnoses were investigated by resident physicians who must follow basal guidelines for dementia investigation from the Swedish NBHW [30].

Nevertheless, the study had a number of limitations. It was not possible to investigate the severity of dementia of residents due to the lack of this information. Since severe dementia according to ICD-10 is defined as a need of permanent support and caregiving from others, all residents of this study were classified as having severe dementia. Another limitation was the lack of information about why 170 elderly residents were "undiagnosed" $\mathrm{NH}$ dementia residents. We assume that these undiagnosed residents either were under basal dementia investigation or did not have a dementia diagnosis that was registered at the time of our data collection.

\section{Psychotropic medication}

The usage of psychotropics is still high and according to several Swedish, Danish and Norwegian studies varies greatly $(39 \%-71 \%)$ due to whether the elderly are institutionalized or not and managed by primary care or specialist clinics $[25,27,28]$. In our study, we show that antipsychotics, anxiolytics, hypnotic/sedatives and antidepressants were used in the NHs to the same degree as the above mentioned with no difference by sex or dementia diagnosis (Table 2).
By dichotomizing the residents into two age groups ( $\leq 85$ and $\geq 86$ years), we showed that those $\leq 85$ years were more frequently treated with antipsychotics (both haloperidol and risperidone), which may be appropriate according to national recommendations for treatment.

\section{Antipsychotics}

Large studies on conventional antipsychotics have shown an association with increased mortality risk in residents with dementia $[15,23]$, with additionally a high prevalence of adverse effects [38-40] such as sedation, delirium, cognitive impairment, increased risk of CVI and extra-pyramidal symptoms $[11,41]$. There have been some changing trends in antipsychotic treatments over the past decade, but still with minor results [24, 42]. In our study population, risperidone was the most common antipsychotic used in residents with dementia (11,5\%) followed by haloperidol $(6,6 \%)$; this could be considered a good treatment policy. However, the relatively large usage of haloperidol $(7,1 \%)$ and the low percentage of quetiapine and olanzapine $(1,9 \%)$ are not in line with recommendations by either the Swedish NBHW, the EMA or the FDA [21, 22, 43]. For example, in a similar population in US NHs, haloperidol treatment was 1,9\% and in a study from Sydney, Australia, the usage of conventional antipsychotics was $7,4 \%$ [44, 45]. Snowdon compared psychotropic medication use in $\mathrm{NHs}$ and noted frequencies of antipsychotics 42,6\% (Finland), 23,8\% (Norway), 28,0\% (Australia) compared to our $21,6 \%$ [45].

As noted, individuals with DLB may have high hypersensitivity to antipsychotics with an increased risk of adverse events such as somnolence, falls, extra-pyramidal symptoms, malignant neuroleptic syndrome and finally increased mortality $[13,16,34]$. In our study, the residents with 2-4 DLB signs received the highest proportion of antipsychotics (32\%) as well as the highest usage of haloperidol (17\%) (Table 2).

There is currently no consensus on evidence-based treatment of NPS in DLB patients either in their homes or in NHs. However, clinical guidelines show beneficial effects from ChEI (donepezil and rivastagmin) and less beneficial effects with both atypical (quetiapine and risperidon) and conventional antipsychotics (haloperidol) [38-40]. Alarmingly, the antipsychotic usage in our study increased with the greater number of DLB clinical signs to as high as $43 \%$, meaning that the most fragile elderly residents had the poorest treatment (Fig. 1). If we assume that these elderly persons have a possible DLB disorder, then all antipsychotic drugs would be highly inappropriate.

We found that antipsychotic treatment varied between $26 \%$ and $28 \%$ in residents with clinical features such as $\mathrm{PD}$, rigidity, balance problems, excessive daytime sleepiness and sleep disorder as well as in $38 \%$ of those with 
visual hallucinations. One disadvantage of our study was the lack of opportunity to perform individual clinical examinations in order to observe, for example, potential extra-pyramidal symptoms due to usage of antipsychotic medication. This was however not practically possible to carry out. The reports from nursing staff is of a more longitudinal character in relation to a doctor's examination. Against this background, the limitation must be considered as minor.

The association between drug use and the number of DLB signs is difficult to establish because the potential side effects of antipsychotics are identical to DLB signs, which represents an important limitation. However, one favourable finding is that those residents with no or one DLB sign had the highest haloperidol doses $(1.5 \mathrm{mg}-$ $2.0 \mathrm{mg}$ ) compared with those with 2-4 DLB signs. This may indicate that the symptoms in the $2-4$ DLB group are less influenced by antipsychotic side effects.

\section{Other psychotropics}

We found that the usage of psychotropics in $78 \%$ of residents was equally distributed between men and women. Comparison of the treatment of our $\mathrm{NH}$ residents with studies from geographically close countries showed similarities in treatment. In a study of Norwegian NHs, $88 \%$ of the elderly residents with dementia had some psychotropic medication [7]. The residents in the present study received psychotropic treatments continuously and over two-thirds had at least one anxiolytic medication, most often oxazepam. NPS such as anxiety, agitation and sleep disturbance are common in the elderly and one explanation for this extensive anxiolytic treatment might be the lower prevalence of adverse events compared with other psychotropics and antipsychotic medications.

Analysis of our two age groups showed that even the older, more fragile individuals ( $\geq 86$ years) had the same amount of anxiolytic medication and hypnotics/sedatives as the younger group ( $\leq 85$ years). According to the Swedish NBHW and the EMA, the prescription of inappropriate medications including psychotropics is not recommended especially for the elderly with dementia [21, 43]. However, a small positive finding from our study was that at least the usage of antipsychotics was higher in the younger and hopefully less fragile residents.

\section{Anti-dementia medication}

We found anti-dementia medication in $45 \%$ of the residents but in none of the residents without a formal dementia diagnosis, which may indicate that the diagnoses from hospital medical records are reliable (Table 3). In our study, there was a difference according to age in anti-dementia treatment showing that younger residents ( $\leq 85$ years) had more anti-dementia medication compared with those $\geq 86$ years. In some respects, this situation may be disadvantageous because the older population with dementia can also have good short-term cognitive response to $\mathrm{ChEI}$ as well as positive long-term effects [46].

Although ChEI are not the first-line medical treatment of NPS, they may reduce the emergence of NPS in the elderly with dementia and play a positive role in reducing these symptoms [47]. Of our $\mathrm{NH}$ residents with a formal DLB/PDD diagnosis, $62 \%$ had anti-dementia medication compared with $35 \%$ of those with 2-4 DLB signs.

In addition, one-third of the residents with 2-4 DLB clinical features were those without a diagnosis. If we assume that they have had undiagnosed dementia since becoming $\mathrm{NH}$ residents, having no formal dementia diagnosis may constitute a disadvantage for these elderly residents in that they miss out on anti-dementia treatment and risk treatment with inappropriate antipsychotics.

Other minor limitations, beside lack of clinical examinations, were that CT/MRI findings and family data were not available. However, observations from the clinical nurses who recorded the clinical features at the time of study suggest that residents with 2-4 DLB signs should be reported to the $\mathrm{NH}$ physicians as high-risk individuals for undiagnosed DLB/PDD and are subsequently unsuited for treatment with psychotropics such as haloperidol and less beneficial anti-dementia treatments.

Nowadays, Swedish NHs may have 30-100 residents with one resident physician responsible for the medical treatment of all these individuals, which implies that collaboration with the nursing staff is crucial. For example, the $\mathrm{NH}$ staff continuously report different medical signs of importance to guide the active physicians working at a $\mathrm{NH}$ to consider different diagnoses. Our study questionnaire was not standardised which may seem as a limitation. However, it was based on the main DLB symptoms described in the consensus criteria. By using the clinical DLB signs from our study questionnaire as an observation manual for $\mathrm{NH}$ staff, we aimed to identify residents with two or more DLB signs and categorize them as at-risk individuals for inappropriate medication who could be reported to the physicians for further treatment or investigation.

\section{Conclusions}

Residents from Swedish NHs with 2-4 clinical DLB signs receive an unfavourable medical treatment with high antipsychotic usage and insufficient anti-dementia medication. These findings show the importance of identifying elderly persons with DLB features more effectively and improving collaboration with nursing staff to provide better medical prescription.

\section{Abbreviations}

AD: Alzheimer's disease; AD-MIX: Alzheimer's disease mixed dementia; CBCT: Cone beam computed tomography; DLB: Dementia with Lewy bodies; EMA: European Medicines Agency; FDA: Food and Drug Administration; MR: Magnetic resonance; NBHW: National Board of Health and Welfare; 
NH: Nursing home; NOS: Not otherwise specified; NPS: Neuropsychiatric symptoms; PDD: Parkinson's disease with dementia; RBD: Sleep behaviour disorder; REM: Rapid eye movement; VaD: Vascular dementia

\section{Acknowledgements}

We would like to thank the nursing staff from the nursing homes in Malmö for assistance in the acquisition of data. We also thank VL for her critical revision of the manuscript and important intellectual content.

\section{Funding}

This study was partially supported by Governmental Funding of Clinical Research within the National Health Services (ALF), Swedish research council nr: 523-2010-520, the Swedish Parkinson Foundation and the Kockska Foundation. The funding bodies were not involved in the study design, data collection, analysis, writing of the manuscript or the decision to submit for publication.

\section{Availability of data and materials}

The datasets generated and/or analysed during the current study are not publicly available but are available from the corresponding author on reasonable request.

\section{Authors' contributions}

IZ was a major contributor in writing the manuscript, data collection, data analysis and the result interpretation. EL was responsible for study concept and design, contributed to the result interpretation, manuscript writing and the critical revision of the manuscript for important intellectual content. GT was responsible for the critical revision of the manuscript and for important intellectual content. CW data interpretation and statistical analysis. All authors read and approved the final manuscript and consented to publish this manuscript.

\section{Ethics approval and consent to participate}

Informed consent forms were given to the head nurses at the $40 \mathrm{NHs}$; they thereafter collected oral informed consent from the residents and/or their family members.

If the resident lacked the capacity to consent himself/herself because of fragility the family member and/or trustee made this decision together with the head nurse before inclusion in the study. The Regional Ethical Review Board in Lund approved this study.

\section{Consent for publication}

Not applicable.

\section{Competing interests}

The authors declare that they have no competing interests.

\section{Publisher's Note}

Springer Nature remains neutral with regard to jurisdictional claims in published maps and institutional affiliations.

\section{Received: 23 August 2017 Accepted: 1 February 2018} Published online: 17 February 2018

\section{References}

1. Ferri CP, Prince $M$, Brayne C, Brodaty H, Fratiglioni L, Ganguli M, et al. Global prevalence of dementia: a Delphi consensus study. Lancet. 2005;366(9503): 2112-7.

2. Wimo A, Jonsson L, Bond J, Prince M, Winblad B, Alzheimer DI. The worldwide economic impact of dementia 2010. Alzheimer's dement. 2013; 9(1):1-11. e3

3. Mollenhauer B, Forstl H, Deuschl G, Storch A, Oertel W, Lewy TC. Body and parkinsonian dementia: common, but often misdiagnosed conditions. Deutsches Arzteblatt international. 2010;107(39):684-91.

4. Zaccai J, McCracken C, Brayne C. A systematic review of prevalence and incidence studies of dementia with Lewy bodies. Age Ageing. 2005;34(6):561-6.

5. Selbaek G, Kirkevold O, Engedal K. The course of psychiatric and behavioral symptoms and the use of psychotropic medication in patients with dementia in Norwegian nursing homes-a 12-month follow-up study. A J Geriatr Psychiatry. 2008;16(7):528-36.
6. Liperoti R, Pedone C, Corsonello A. Antipsychotics for the treatment of behavioral and psychological symptoms of dementia (BPSD). Curr Neuropharmacol. 2008;6(2):117-24.

7. McKeith IG, Dickson DW, Lowe J, Emre M, O'Brien JT, Feldman H, et al. Diagnosis and management of dementia with Lewy bodies: third report of the DLB consortium. Neurology. 2005;65(12):1863-72.

8. McKeith I, Mintzer J, Aarsland D, Burn D, Chiu H, Cohen-Mansfield J, et al. Dementia with Lewy bodies. The Lancet Neurology. 2004;3(1):19-28.

9. McKeith IG, et al. Diagnosis and management of dementia with Lewy bodies: fourth consensus report of the DLB consortium. Neurology 2017; 89(1):88-100.

10. Fujimi K, Sasaki K, Noda K, Wakisaka Y, Tanizaki Y, Matsui Y, et al. Clinicopathological outline of dementia with Lewy bodies applying the revised criteria: the Hisayama study. Brain Pathol. 2008;18(3):317-25.

11. Ballard C, Howard R. Neuroleptic drugs in dementia: benefits and harm. Nat Rev Neurosci. 2006;7(6):492-500.

12. Wang PS, Schneeweiss S, Avorn J, Fischer MA, Mogun $H$, Solomon DH, et al. Risk of death in elderly users of conventional vs. atypical antipsychotic medications. N Engl J Med. 2005;353(22):2335-41.

13. Langballe EM, Engdahl B, Nordeng H, Ballard C, Aarsland D, Selbæk G. Short- and long-term mortality risk associated with the use of antipsychotics among 26,940 dementia outpatients: a population-based study. Am J Geriatr Psychiatry. 2014;22(4):321-31.

14. Rongve A, Vossius C, Nore S, Testad I, Aarsland D. Time until nursing home admission in people with mild dementia: comparison of dementia with Lewy bodies and Alzheimer's dementia. International journal of geriatric psychiatry. 2014;29(4):392-8.

15. Gill SS, Bronskill SE, Normand SL, Anderson GM, Sykora K, Lam K, et al. Antipsychotic drug use and mortality in older adults with dementia. Ann Intern Med. 2007;146(11):775-86.

16. Schneider LS, Dagerman K, Insel PS. Efficacy and Adverse effects of atypical antipsychotics for dementia: meta-analysis of randomized, placebocontrolled trials. Am J Geriatr Psychiatry. 2006;14(3):191-210.

17. Swanberg MM, Cummings JL. Benefit-risk considerations in the treatment of dementia with Lewy bodies. Drug Saf. 2002;25(7):511-23.

18. McKeith I, Fairbairn A, Perry R, Thompson P, Perry E. Neuroleptic sensitivity in patients with senile dementia of Lewy body type. BMJ. 1992;305(6855):673-8.

19. Aarsland D, Ballard C, Walker Z, Bostrom F, Alves G, Kossakowski K, et al. Memantine in patients with Parkinson's disease dementia or dementia with Lewy bodies: a double-blind, placebo-controlled, multicentre trial. The Lancet Neurology. 2009;8(7):613-8.

20. FDA: 2008 Information on Conventional Antipsychotics [Internet]. U.S. Food and Drug Administration. 6/16/2008.

21. Welfare TSNBoHa. The usage of antipsychotic medication according to Swedish National Board of Health and Welfare "Användning av antipsykotiska läkemedel hos äldre". 2015.

22. EMEA EMA. European Medicines Agency: CHMP assessment report on conventional antipsychotics. Procedure under Article 5(3) of Regulation (EC) No 726/2004. 2004:590557/2008.

23. Schneeweiss S, Setoguchi S, Brookhart A, Dormuth C, Wang PS. Risk of death associated with the use of conventional versus atypical antipsychotic drugs among elderly patients. CMAJ. 2007;176(5):627-32.

24. Guthrie B, Clark SA, Reynish EL, McCowan C, Morales DR. Differential impact of two risk communications on antipsychotic prescribing to people with dementia in Scotland: segmented regression time series analysis 2001-2011. PLoS One. 2013;8(7):e68976.

25. Giron MS, Forsell Y, Bernsten C, Thorslund M, Winblad B, Fastbom J. Psychotropic drug use in elderly people with and without dementia. International journal of geriatric psychiatry. 2001;16(9):900-6.

26. Kales HC, Zivin K, Kim HM, Valenstein M, Chiang C, Ignacio RV, et al. Trends in antipsychotic use in dementia 1999-2007. Arch Gen Psychiatry. 2011:68(2):190-7.

27. Bergman A, Olsson J, Carlsten A, Waern M, Fastbom J. Evaluation of the quality of drug therapy among elderly patients in nursing homes. Scand J Prim Health Care. 2007:25(1):9-14.

28. Zakarias JK, Jensen-Dahm C, Norgaard A, Stevnsborg L, Gasse C, Andersen $B G$, et al. Geographical variation in antipsychotic drug use in elderly patients with dementia: a Nationwide study. Journal of Alzheimer's disease: JAD. 2016:54(3):1183-92.

29. Zahirovic I, Wattmo C, Torisson G, Minthon L, Londos E. Prevalence of dementia with Lewy body symptoms: a cross-sectional study in 40 Swedish nursing homes. J Am Med Dir Assoc. 2016;17(8):706-11. 
30. The Swedish National Board of Health and Welfare. National Guidelines for Health and Social Care for demented elderly 2016/Nationella riktlinjer för vård och omsorg vid demenssjukdom. 2016.

31. Lewy Body Dementia Association. Lewy Body Dementia Diagnostic Symptoms. https://www.lbda.org/content/symptoms, 2016.

32. Dunkel M, Gunther S, Ahmed J, Wittig B, Preissner R. SuperPred: drug classification and target prediction. Nucleic Acids Res. 2008;36(Web Server): W55-9.

33. Aarsland D, Rongve A, Nore SP, Skogseth R, Skulstad S, Ehrt U, et al. Frequency and case identification of dementia with Lewy bodies using the revised consensus criteria. Dement Geriatr Cogn Disord. 2008;26(5):445-52.

34. Bostrom F, Jonsson L, Minthon L, Londos E. Patients with dementia with lewy bodies have more impaired quality of life than patients with Alzheimer disease. Alzheimer Dis Assoc Disord. 2007;21 (2):150-4.

35. Heidebrink JL. Is dementia with Lewy bodies the second most common cause of dementia? J Geriatr Psychiatry Neurol. 2002;15(4):182-7.

36. Howard R, McShane R, Lindesay J, Ritchie C, Baldwin A, Barber R, et al. Nursing home placement in the donepezil and Memantine in moderate to severe Alzheimer's disease (DOMINO-AD) trial: secondary and post-hoc analyses. The Lancet Neurology. 2015;14(12):1171-81.

37. Kales HC, Valenstein M, Kim HM, McCarthy JF, Ganoczy D, Cunningham F, et al. Mortality risk in patients with dementia treated with antipsychotics versus other psychiatric medications. Am J Psychiatry. 2007;164(10):1568-76. quiz 623

38. Stinton C, McKeith I, Taylor JP, Lafortune L, Mioshi E, Mak E, et al. Pharmacological Management of Lewy Body Dementia: a systematic review and meta-analysis. Am J Psychiatry. 2015;172(8):731-42.

39. Prohorov T, Klein C, Miniovitz A, Dobronevsky E, Rabey JM. The effect of quetiapine in psychotic parkinsonian patients with and without dementia. An open-labeled study utilizing a structured interview. J Neurol. 2006;253(2): $171-5$.

40. Kurlan R, Cummings J, Raman R, Thal L. Alzheimer's disease cooperative study G. Quetiapine for agitation or psychosis in patients with dementia and parkinsonism. Neurology. 2007;68(17):1356-63.

41. Vigen CL, Mack WJ, Keefe RS, Sano M, Sultzer DL, Stroup TS, et al. Cognitive effects of atypical antipsychotic medications in patients with Alzheimer's disease: outcomes from CATIE-AD. Am J Psychiatry. 2011:168(8):831-9.

42. Vasudev A, Shariff SZ, Liu K, Burhan AM, Herrmann N, Leonard S, et al. Trends in psychotropic dispensing among older adults with dementia living in long-term care facilities: 2004-2013. Am J Geriatr Psychiatry. 2015;23(12): 1259-69.

43. Agency MP. Läkemedelsbehandling och bemötande vid Beteendemässiga och Psykiatriska Symptom vid Demenssjukdom-BPSD. 2008;5:15-24.

44. Kamble P, Chen H, Sherer J, Aparasu RR. Antipsychotic drug use among elderly nursing home residents in the United States. Am J Geriatr Pharmacother. 2008;6(4):187-97.

45. Snowdon J, Galanos D, Vaswani D. Patterns Of psychotropic medication use in nursing homes: surveys in Sydney, allowing comparisons over time and between countries. International psychogeriatrics / IPA. 2011;23(9):1520-5.

46. Wattmo C, Wallin AK, Londos E, Minthon L. Predictors of long-term cognitive outcome in Alzheimer's disease. Alzheimers Res Ther. 2011;3(4):23.

47. Cummings J, Lai TJ, Hemrungrojn S, Mohandas E, Yun Kim S, Nair G, et al. Role of donepezil in the Management of Neuropsychiatric Symptoms in Alzheimer's disease and dementia with Lewy bodies. CNS neuroscience \& therapeutics. 2016;22(3):159-66.

\section{Submit your next manuscript to BioMed Centra and we will help you at every step:}

- We accept pre-submission inquiries

- Our selector tool helps you to find the most relevant journal

- We provide round the clock customer support

- Convenient online submission

- Thorough peer review

- Inclusion in PubMed and all major indexing services

- Maximum visibility for your research

Submit your manuscript at www.biomedcentral.com/submit 